\section{ROCURONIUM VERSUS CISATRACURIUIM: INTUBATING CONDITIONS, EFFICACY, AND SAFETY.}

KEY WORDS: Neuromuscular blocking drugs, intubating conditions, hemodynamic stability.

\section{Deba Gopal Pathak}

\section{Poonam Sharma*}

Professor and HOD Department of Anesthesiology and Critical Care Silchar Medical College and Hospital.

Post graduste trainee Department of Anesthesiology and Critical Care Silchar Medical College and Hospital. *Corresponding Author

Background: Neuromuscular blockers (NMB) are very important adjuvant to general anesthesia, Rocuronium bromide (aminosteroidal NMB) and cisatracurium besylate (benzylisoquinoline NMB) are recently introduced non-depolarizing muscle relaxants. In a prospective randomized study, we had compared both the drugs as regard to the onset of action, intubating conditions, clinical duration, hemodynamic changes, and adverse effects.

Method: 80 female patients ASA I\&II, 18-60 year old underwent elective abdominal surgery under general anesthesia (GA) were randomly assigned into 2 equal groups. ROC group, where $0.9 \mathrm{mg} / \mathrm{kg}$ rocuronium was given and CIS group, where $0.15 \mathrm{mg} / \mathrm{kg}$ cisatracurium was given. Standardized GA was given to all patients as follows, fentanyl lmcg/kg, propofol $2 \mathrm{mg} / \mathrm{kg}$, intubation was tried by the same anesthetist who was blind to the given NMB after 60 sec of injection, intubation was done if the intubating condition was acceptable (excellent or good), and it was re-attempted every 30 sec if it was poor or inadequate. Anesthesia was maintained by $60 \% \mathrm{~N} 2 \mathrm{O}$ in $\mathrm{O} 2$ and isoflurane to a total MAC 1.5, controlled ventilation was adjusted to normocapnia. Mean arterial blood pressure (MAP), heart rate, and intubating conditions were recorded.

Results: Clinically acceptable intubating conditions were achieved after $60 \mathrm{sec}$ more frequently with rocuronium (80\%) than with cisatracurium( $0 \%)$. Rocuronium had advantage of rapid onset of action with good intubating conditions as compared to Cisatracurium and both were found to be potent and safe with excellent cardiovascular stability and also without any apparent histamine release.

Conclusion: Rocuronium has a rapid onset of action with good intubating conditions in comparison to cisatracurium both are potent and safe with excellent cardiovascular stability and do not cause apparent histamine release

\section{INTRODUCTION}

Neuromuscular blockers (NMB) became an essential part of the anesthetist armamentarium. They aid endotracheal intubations, mechanical ventilation, decrease anesthetic requirement, prevent patient movement, facilitate surgery, and decrease oxygen consumption.

The drug named d-tubocurarine was the first skeletal muscle relaxant introduced in the year 1942 which was nondepolarizing in nature and was used to fulfil the need for jaw relaxation. Even in clinical doses, this drug provided excellent muscle relaxation however, it had additional ganglion blocking properties which resulted in tachycardia, hypotension. Further, in emergency cases, because of its action delayed on the onset of jaw relaxation, making it quite ill-suited for usage during rapid sequence intubation. Thus, an extensive hunt began for a relaxant which had a short duration of action and a rapid onset. ${ }^{1}$ Rocuronium bromide is a new aminosteroidal non-depolarizing NMB. It is monoquaternary analogue of vecuronium and is primarily eliminated via biliary excretion and hepatic reuptake, and up to $20 \%$ is excreted unchanged through urine. ${ }^{2}$ It has one metabolite 17-desacetyl Rocuronium which has only 5-10\% activity of the parental compound and further does not trigger the release of histamine.The adult ED95 is $0.3 \mathrm{mg} / \mathrm{kg}^{3}$

Cisatracurium, besylate is a new benzylisoquinoline NMB introduced for clinical use in 1995 with no histamine release and better haemodynamic stability. It is basically a purified from of one of the 10 stereo-isomers of atracurium and is mainly degraded by Hofmann elimination and has got one metabolite laudanosine which has no NMB effect. The adult ED95 is $0.05 \mathrm{mg} / \mathrm{kg}^{4,5,6}$

Although Cisatracurium is more potent than the parent mixture ( $95 \%$ effective dose [ED] $0.05 \mathrm{mg} / \mathrm{kg}$ vs $0.2 \mathrm{mg} / \mathrm{kg})^{7,8}$, its pharmacodynamic profile is similar to that of atracurium, except for a reportedly sluggish onset time of 3.1-5.2 min at 2 times the ED, for neuromuscular blockade. ${ }^{9,10}$

\section{METHOD OF STUDY}

Eighty adult female patients underwent elective abdominal surgery under general anesthesia in Silchar Medical College and Hospital were enrolled in the study after approval by our local ethics committee and after taking informed written consent from the patients. The patients were of ASA physical status 1\&2, Mallampati class I\&IIand their age ranged18-60 years.

Exclusion criteria included patients having major hepatic, renal, cardiovascular, pulmonary and neuromuscular diseases. Morbidly obese, pregnant and patients under anticonvulsant, calcium channel blockers, B-blockers, steroids, frusemide, or aminoglycoside therapy were also excluded.

All patients were preoperatively evaluated by history taking, full clinical examination, ECG, and some laboratory investigations for the presence of inclusion and exclusion criteria.

The patients were randomly assigned into 2 equal groups of 40 patients each, in the first group Rocuronium $0.9 \mathrm{mg} / \mathrm{kg}$ was examined [group ROC], while in the second group Cisatracurium $0.15 \mathrm{mg} / \mathrm{kg}$ was examined [group CIS].

\section{ANESTHETICTECHNIQUE}

After arrival of the patient in the operating room without premedication, an IV line was secured in any forearm with an appropriate sized cannula and the patient was monitored for ECG tracing, heart rate, non-invasive arterial blood pressure, and spo2, end tidal $\mathrm{CO}_{2}$ was also monitored-. Anaesthesia machine, circuits were checked for proper functioning, and resuscitation drugs and equipments were kept ready.

The baseline pulse rate, MAP, SpO2 \%, respiration rate were 
recorded (T). Continuous monitoring of the vital parameters was done thereafter. I V fluids were started with $500 \mathrm{ml}$ of Ringer lactate in all patients.

Patients were pre-medicated with following drugs;

- Inj.Fentanyl $\mathrm{lmcq} / \mathrm{kg}$ i.v stat.

- Inj. Glycopyrrolate $0.2 \mathrm{mg}$ i.v stat

In both Groups after preoxygenation with $100 \%$ oxygen for 3 mins, anaesthesia was induced with $2 \mathrm{mg} / \mathrm{kg}$ of intravenous propofol.

Cisatracurium $0.15 \mathrm{mg} / \mathrm{kg}$ IV was given in patients in the group A and Rocuronium bromide $0.9 \mathrm{mg} / \mathrm{kg}$ IV was given in patients in group B. Orotracheal intubation was performed by the same anaesthetist who was blind to the given NMB. After 60seconds of its injection, the intubating conditions were assessed using a four point score [excellent, good, poor, or inadequate]. If the intubating condition was excellent or good, tracheal intubation was performed, and if it was poor or inadequate, intubation was postponed and was re-attempted every 30 second. Anaesthesia was maintained with $60 \% \mathrm{~N}_{2} \mathrm{O}$ in $\mathrm{O}_{2}$ and isoflurane to a total MAC 1.5.1

Mechanical ventilation was adjusted to maintain end tidal $\mathrm{CO}_{2}$ between 35-40 mmhg. Ringers lactate was infused at rate 7 $\mathrm{ml} / \mathrm{kg} / \mathrm{h}$. Surface warming was applied to maintain oesophageal temperature between 36-37 degree Celsius. According to requirement, top-up doses of NMB were administered during surgery. At the end of operation, the muscle relaxant effect was reversed by using neostigmine and atropine/ glycopyrrolate.

\section{CLINICAL MEASUREMENT:}

A) Hemodynamic variables Mean arterial blood pressure (MAP) and heart rate (HR) were recorded at the following intervals

- T:baseline

- T0: before induction

- Tl:after induction

- T2:just after intubation.

- And then every 5 minutes for 30 min after intubation.

\section{B) Intubation score}

This was done by 4 points scale:

Excellent: relaxed jaw, abducted immobile vocal cords, and no diaphragmatic movement.

Good: relaxed jaw, abducted immobile vocal cords, and some diaphragmatic movement (bucking).

Poor: relaxed jaw, moving vocal cords, coughing on intubation.

Inadequate: jaw is not relaxed, adducted vocal cords, and impossible intubation.

C) Adverse events Any adverse events like histamine release in the form of skin reaction, bronchospasm, wheeze, increased airway pressure, $\mathrm{O} 2$ desaturation, or hypotension were recorded. Any postoperative pain at the site of injection of NMB was also recorded.

\section{STATISTICS}

All data are presented as Mean \pm SD (Standard Deviation). All Quantitative data are assessed using Student's t - test to analyse changes over a period of time. Qualitative data are assessed using Fisher exact Test or Chi-square test.

\section{RESULTS}

Both groups were comparable as regard age, weight, Mallampati class, height, and the duration of operation (table 1).
Table 1: Demographic characteristics in both groups (Mean \pm SD)

\begin{tabular}{|l|c|c|}
\hline & ROC & CIS \\
\hline Age(yrs) & $35.2 \pm 11.9$ & $36.4 \pm 11.7$ \\
\hline Weight(kgs) & $62.9 \pm 8.3$ & $61.7 \pm 7.4$ \\
\hline Height (cms) & $163 \pm 3.4$ & $164.7 \pm 3.7$ \\
\hline Duration of surgery & $65.8 \pm 4.5$ & $65.5 \pm 5.2$ \\
\hline
\end{tabular}

As regard hemodynamic variables, there was transient insignificant decrease in mean arterial blood pressure (MAP) after induction followed by return to the baseline after intubation without intergroup difference (table 2). Also, there was transient insignificant decrease in mean HR after induction followed by tachycardia after intubation in patients of both the groups who required no treatment and of no clinical significance.

Table 2: Changes in mean arterial blood pressure (MAP) in both groups

\begin{tabular}{|l|l|l|l|l|l|}
\hline \multicolumn{3}{|l}{ Mean Arterial Pressure } & \multirow{2}{*}{ P value } \\
\cline { 1 - 5 } & GROUP A (CIS) & \multicolumn{2}{l}{ GROUP B(ROC) } & \\
\cline { 1 - 4 } & Mean & SD & Mean & SD & \\
\hline T & 97.4 & \pm 2.3 & 96.17 & \pm 4.8 & 0.131 \\
\hline T0 & 97.3 & \pm 2.6 & 96 & \pm 5.0 & 0.149 \\
\hline T1 & 91.5 & \pm 2.25 & 90.02 & \pm 5.16 & 0.091 \\
\hline T2 & 102.12 & \pm 2.96 & 100.7 & \pm 4.1 & 0.100 \\
\hline T3 & 96.9 & \pm 2.5 & 95.9 & \pm 2.9 & 0.110 \\
\hline T4 & 97.4 & \pm 2.3 & 96.175 & \pm 4.8 & 0.131 \\
\hline T5 & 97.7 & \pm 2.8 & 96.35 & \pm 4.09 & 0.080 \\
\hline T6 & 97.5 & \pm 3.12 & 96.4 & \pm 3.5 & 0.175 \\
\hline T7 & 97.6 & \pm 3.10 & 96.17 & \pm 4.8 & 0.121 \\
\hline T8 & 97.7 & \pm 3.2 & 96.47 & \pm 3.5 & 0.105 \\
\hline
\end{tabular}

Table 3: Changes in heart rate (HR) in both groups

\begin{tabular}{|c|c|c|c|c|c|}
\hline \multirow{2}{*}{} & \multicolumn{4}{|c|}{ Heart rate (beats/min) } & \multirow{2}{*}{ P value } \\
\cline { 2 - 5 } & \multicolumn{2}{|c|}{ GROUP A (CIS) } & \multicolumn{1}{c|}{ GROUP B (ROC) } & \\
\cline { 2 - 5 } & Mean & SD & Mean & SD & \\
\hline HR T & 89.3 & \pm 8.2 & 87.4 & \pm 6.6 & 0.241 \\
\hline HR T0 & 89.5 & \pm 7.5 & 87.7 & \pm 6.3 & 0.252 \\
\hline HR T1 & 84.4 & \pm 7.5 & 82.4 & \pm 6.7 & 0.210 \\
\hline HR T2 & 97.7 & \pm 8.8 & 95.7 & \pm 7.1 & 0.270 \\
\hline HR T3 & 92.4 & \pm 8.5 & 89.9 & \pm 7.1 & 0.151 \\
\hline HR T4 & 89.3 & \pm 8.2 & 87.4 & \pm 6.6 & 0.241 \\
\hline HR T5 & 89.9 & \pm 7.6 & 87.9 & \pm 6.3 & 0.208 \\
\hline HR T6 & 89.8 & \pm 6.9 & 88.3 & \pm 6.4 & 0.318 \\
\hline HR T7 & 89.6 & \pm 7.15 & 87.9 & \pm 6.3 & 0.245 \\
\hline HR T8 & 89.9 & \pm 7.17 & 87.4 & \pm 6.6 & 0.106 \\
\hline
\end{tabular}

The intubating conditions at $60 \mathrm{sec}$ were excellent in 20 patients (50\%) and good in 12 patients (30\%) in ROC group. On the contrary, there were no excellent or good intubating conditions in CIS group. At $90 \mathrm{sec}$, the intubating conditions were excellent in 6 patients (15\%) and good in 2 patients $(5 \%)$ in ROC group. There were no excellent but only 2 good intubating conditions (5\%) in CIS group. At 120 sec, the intubating conditions were excellent in 2 patients (5\%) and good in 2 patients (5\%) in CIS group. At 150 sec, the intubating conditions were excellent in 14 patients (35\%) and good in 16 patients (40\%) in CIS group. At $180 \mathrm{sec}$, there were 4 excellent intubating conditions (10\%) in CIS group as shown in table 4.

In ROC group, the intubation was performed in 32 patients after $60 \mathrm{sec}$ and in 8 patients after $90 \mathrm{sec}$. In CIS group, the intubation was performed in 2 patients after $90 \mathrm{sec}$, in 4 patients after $120 \mathrm{sec}$, in 30 patients after $150 \mathrm{sec}$ and in 4 patients after $180 \mathrm{sec}$.

Table (4): The intubating conditions at different time intervals (sec) in both groups

\begin{tabular}{|l|l|l|l|l|l|}
\hline $\begin{array}{l}\text { Intubating } \\
\text { conditions }\end{array}$ & 60 secs & 90 secs & 120 sec & $\begin{array}{l}150 \\
\text { secs }\end{array}$ & 180 secs \\
\hline
\end{tabular}

|www.worldwidejournals.com $\mid$ 


\begin{tabular}{|l|l|l|l|l|l|l|l|l|l|l|}
\hline & ROC & CIS & ROC & CIS & ROC & CIS & ROC & CIS & ROC & CIS \\
\hline Excellent & 20 & -- & 6 & -- & - & 2 & -- & 14 & -- & 4 \\
\hline Good & 12 & -- & 2 & 2 & -- & 2 & -- & 16 & -- & -- \\
\hline Poor & 8 & 40 & -- & 38 & -- & 34 & -- & -- & -- & -- \\
\hline Intubation & 32 & & 8 & 2 & & 4 & & 30 & & 4 \\
\hline
\end{tabular}

In ROC group, the intubation was performed in 32 patients after 60 sec and in 8 patients after 90 sec with mean intubation time 66.8+9.4sec.In CIS group, the intubation was performed in 2 patient after $90 \mathrm{sec}$, in 4 patients after $120 \mathrm{sec}$, in 30 patients after 150 sec and in 4 patients after 180 sec with mean intubation time $147.5+2.2 \mathrm{sec}$

In our study we didn't notice any incidence of histamine release indicating symptoms like bronchospasm, intraoperative skin reactions, fever, hypotension, vomiting, desaturation, tachycardia etc. Other side effects like burning sensation during administration of Rocuronium at the site of injection was seen in some cases, but it required no intervention and incidence was also not significant.

\section{DISCUSSION}

From South American Indian's arrow poison or curares, the use of neuromuscular blocking drugs originates. Dtubocurarine was initially used, but the hunt for other neuromuscular blocking drugs resulted because of increased incidence of mortality. Due to its quick onset and short duration of action, which enabled rapid tracheal intubation, succinylcholine introduced by Thesleff and Foldes in 1952 changed the anaesthetic practice.

Baird and Reid in 1967 first reported the use of aminosteroid Pancuronium which was not having ganglionic blocking and histamine releasing properties and also was vagolytic. Since then numerous non depolarizing muscle relaxants like pipecuronium, doxacurium, atracurium, cis atracurium, rapacuronium, vecuronium and Rocuronium were introduced, each with an advancement over their predecessor.

New non depolarizing muscle relaxant was introduced in 1995 in anaesthetic field i.e Cisatracurium besylate as a new benzyl isoquinoline NMB which is 3-4 times more potent than atracurium is a purified form of the 10 stereo-isomers of atracurium ,it is eliminated mainly by Hofmann degradation and also it does not trigger histamine release and is known for its hemodynamic stability with intermediate duration of action.

This study was performed to compare Rocuronium and Cisatracurium with regard to onset of action, intubating conditions, hemodynamic stability and adverse effects. The study was conducted in Silchar Medical College and Hospital, Silchar, Assam. The study was performed within the period from 01/06/2019 to 31/05/2020.

The study population consisted of 80 patients divided equally in two groups. Patients in group A received inj. Cisatracurium and patients in group $B$ received inj. Rocuronium

The intubating conditions at $60 \mathrm{sec}$ after rocuronium were clinically acceptable in about $80 \%$ of patients in our study and this is similar to the results of Chetty et $\mathrm{al}^{11}$. In consistent with our results Zhou et al reported $84 \%$ clinically accepted intubating conditions after 60 sec. In contrast, Pino et $\mathrm{al}^{12}$ found that only $40 \%$ of intubation to be acceptable at 90 sec. The intubating conditions after cisatra-curium in our study were only acceptable after $150 \mathrm{sec}$ and this was similar to the results of Doenicke et $\mathrm{al}^{13}$. In contrast, Kim et $\mathrm{al}^{14}$ reported acceptable intubating condition after $3 \mathrm{~min}$. Because of the rapid onset of rocuronium and the acceptable intubating conditions after $60 \mathrm{sec}$, rocu-ronium was used for rapid sequence intubation ${ }^{15,16,17}$

There were no evidences of any significant clinical cardiovascular changes in both the groups. The heart rates were significantly elevated in both groups after intubation only and this was consistent with Schultz et al ${ }^{18}$ who reported a lack of cardiovascular responses throughout a wide clinical dose range of rocuronium, also Levy et al observed no doserelated changes in heart rate and blood pressure after rocuronium. Reich et $\mathrm{al}^{19}$ demonstrated similar safe cardiovascular changes after cisatracurium in patients with coronary heart disease.

There were no signs of histamine release in both groups in our study but McD Neal et al ${ }^{20}$ reported bronchospasm in 1 of 350 patients after rocuronium, also Doenicke et $\mathrm{al}^{21}$ suggested that cisatracurium has caused modest chemically mediated histamine release but it did not seem to be of clinical significance in their study.

There was burning pain at the site of injection of NMB in few patients after rocuronium. This was also documented by Ruetsch et $\mathrm{al}^{22}$ who reported withdrawal movements associated with the injection of rocuronium.

Although the mechanism by which rocuronium caused pain was unclear; the relatively low PH (4) might be a possible cause as Klement et al ${ }^{23}$ reported, while Borgeat et $\mathrm{al}^{24}$ postulated the release of mediator such as kininogen as the probable cause. There were many studies comparing different strategies to reduce the pain associated with IV administration of rocuronium ${ }^{25,26 .}$

\section{REFERENCES:}

1. Savarase JJ: The autonomic margin of safety of metacurine and dtubocurarine in the cat, Anaesthesiology, 1979;50:40.

2. Hunter JM. Rocuronium: The newest aminosteroidal neuromuscular blocking drug. BrJAnesth 1996;76:481.

3. Kopman AF, Chin WA, Moe J, et al. Effect of N2O on the dose-response relationship of Rocuronium. Anesth\&Analg 2005; 100:1343.

4. Carroll M T, Mirakhur RK, Lowry D, et al. Neuromuscular blocker effects and TOF fade with Cisatracurium: compare-ison with other non-depolarizing relaxants. Anaesthesia 1998;53:1169

5. Belmont M R, Lien CA, Quessy S, et al. The clinical neuromuscular pharmacology of 51 W89 in patients receiving nitrous oxidelopioidlbarbiturate anaesthesia. Anesthesiology 1995;82: 1139-45.

6. Lepage JY, Malinovsky JM, Malinge M, et al. Pharmacodynamic doseresponse and safety study of Cisatracurium (51W89) in adult surgical patients during N,O-O,-opioid anaesthesia. Anesth Analg 1996;83:823-9.

7. Lepage JY, Malinovsky JM, Maligne M, et al. Comparison of equipotent doses of 51 W89 and atracurium [abstract]. Anesthesiology 1994;81:A1090

8. Mellingho ff H, Radbruch L, Diefenbach C, Buzello W. A comparison of Cisatracurium and atracurium: onset of neuromuscular block after bolus injection and recovery after subsequent infusion. Anesth Analg 1996;83:1072-5.

9. Schmautz E, Deriaz H, Vrillon M, Lienhart A. Evaluation of 51 W89 for endotracheal intubation in surgical patients during $\mathrm{N}, \mathrm{O} / \mathrm{O}, /$ propofol anaesthesia [abstract]. Anesthesiology 1994;81:A108

10. Doenicke A, Soukup J, Hoernecke R, Moss J.The lack of histamine release with Cisatracurium: a double blind comparison with vecuronium. Anesth Analg 1997;84:623-8.

11. Chetty MS, Pollard BJ, Witson A, et al Rocuronium bromide in dental day case anesthesia: A comparison with atracurium and vecuronium. Anesth \& Int Care 1996;24:37.

12. Pino RM, Ali HH, Denman WT, et al. Acomparison of intubation condi-tions between mivacurium and rocuronium during balanced anesthesia. Anesthesiology 1998;88:673.

13. Doenicke AW, Czeslick E, Moss J, et al.Onset time, endotracheal intubation, and plasma histamine after cisatracurium and vecuronium administration.Anesth \&Analg 1998;87:434.

14. Kim KS, Chung CW, Chin WJ.Cisatracurium neuromuscular block at the adductor pollicis and the laryngeal adductor muscles in humans. BJA 1999;83:483.

15. McCourt KC, Salmela L, Carroll M, et al.Comparison of rocuronium and suxamethonium for use during rapid sequence induction of anesthesia. BJA 1997;79:134.

16. Heier $\mathrm{T}$ and Caldwell JE. Rapid tracheal intubation with large-dose rocuronium: A probability-based approach. Anesth \&Analg 2000;90:157.

17. Chiu JW, and White PF. The pharmacoeconomics of neuromuscular blocker drugs. Anesth \&Analg 2000;90:S19.

18. Schultz P, Ibsen M, Ostergaard D, et al.Onset and duration of action of rocuronium from tracheal intubation,through intense block to complete recovery. Acta Anesth Scand 2001;45:612.

19. Reich DL, Mulier J,Viby-Mogensen J, et al. Comparison of the cardio-vascular effects of cisatracurium and atracurium in patients with coronary artery disease.Canada JAnesth 1998; 45:794.

20. McD Neal, Manthri P, Gadiyar V, et al.Histaminoid reactions associated with rocuronium. BJA 2000;84:108.

21. Doenicke AW, Czeslick E, Moss J, et al.Onset time, endotracheal intubation, and plasma histamine after cisatracurium and vecuronium administration. Anesth \&Analg 1998;87:434. 
PARIPEX - INDIAN JOURNAL OF RESEARCH | Volume - 10 | Issue - 04 |April - 2021 | PRINT ISSN No. 2250 - 1991 | DOI : $10.36106 /$ paripex

22. Ruetsch YA, Borgeat $A$, and Chevchenko YO. Withdrawal movements associated with the injection of rocuronium. Anesth \& Analg 2000;90:227.

23. Klement $\mathrm{W}$ and Arndt $\mathrm{L}$. Pain on IV injection of some anesthetic agents is evoked by the non physiologic osmolality or $\mathrm{pH}$ of their formulation. $\mathrm{BrJ}$ Anesth 1991;66:189.

24. Borgeat $A$ and Kwiatkowski D.Spontaneous movements associated with rocuronium:Is pain on injection the cause? BrJAnesth 1997;79:382.

25. Chiarella AB, Jolly DT, Huston CM, et al. Comparison of four strategies to reduce the pain associated with IV administration of rocuronium. BJA 2003;90:3

26. Ahmed N, Choy CY, Aris EA, et al Preventing the withdrawal response associated with rocuronium injection: A comparison of fentanyl with xylocaine.Anesth \& Analg 2005; 100:987. 